\title{
Isolation and characterisation of sialidase from a strain of Streptococcus oralis
}

\author{
H. L. BYERS, E. TARELLI, K. A. HOMER and D. BEIGHTON \\ J oint Microbiology Research Unit, GKT Dental Institute, London SE5 9RW
}

\begin{abstract}
Streptococcus oralis, the most virulent of the viridans streptococci, produces a sialidase and this exo-glycosidase has been implicated in the disease process of a number of pathogens. The sialidase of $\mathrm{S}$. oralis strain AR 3 was purified in order to understand the characteristics of this putative virulence determinant. The enzyme isolated as a high mol.wt aggregate (c. $325 \mathrm{kDa}$ ) was purified 4520 -fold from late exponential phase cultures by a combination of ultrafiltration, ammonium sulphate precipitation, ionexchange and gel filtration chromatography. The sialidase component had a mol.wt of $144 \mathrm{kDa}$ as determined by SDS-PAGE analysis. The purified sialidase released $\mathrm{N}$ acetylneuraminic acid from a range of sialoglycoconjugates including human $\boldsymbol{\alpha}_{1}$-acid glycoprotein, bovine submaxillary mucin, colominic acid and sialyl- $\alpha 2,3-$ and sialyl- $\alpha 2,6-$ lactose. Also, $\mathrm{N}$-glycolylneuraminic acid was cleaved from bovine submaxillary mucin. The sialidase had a $\mathrm{K}_{\mathrm{m}}$ of $11.8 \boldsymbol{\mu} \mathrm{M}$ for $\boldsymbol{\alpha}_{1}$-acid glycoprotein, was active over a broad $\mathrm{pH}$ range with a $\mathrm{pH}$ optimum of 6.0 and cleaved $\alpha 2,3-, \alpha 2,6-$ and $\alpha 2-8-$ sialyl glycosidic linkages with a marked preference for $\alpha 2,3$-linkages. The enzyme was competitively inhibited by the sialic acid derivative, 2,3-dehydro- $\mathrm{N}$-acetylneuraminic acid, with a $\mathrm{K}_{\mathrm{IC}}$ of $1.2 \mu \mathrm{M}$. The characteristics of the purified sialidase would support a nutritional role for this enzyme that may be significant in the proliferation of this organism in the oral cavity and at extra-oral sites in association with life-threatening infections.
\end{abstract}

\section{Introduction}

The viridans streptococci have been traditionally regarded as minor opportunist pathogens, being primarily associated with dental caries [1]. However, over the past decade these bacteria have emerged as significant pathogens of immunocompromised patients and those with haematological malignancies [2-5]. Primary bacteraemia in susceptible patient groups is associated with secondary complications that include infective endocarditis, adult respiratory distress syndrome and streptococcal shock resulting in mortality rates of up to $30 \%[6,7]$. Treatment of infections caused by viridans streptococci is becoming more problematic: therapy with penicillins was once a standard regimen but has become less effective because of the emergence of high levels of antimicrobial resistance within this group of organisms [8].

Received 25 Feb. 1999; revised manuscript received 23 J une 1999; accepted 12 Aug. 1999.

Corresponding author: Dr H. L. Byers (e-mail: helen.byers@ kcl.ac.uk).
The viridans streptococci are a highly heterogeneous group of organisms and it is only with the advent of modern typing schemes that it has been possible to associate specific diseases with the isolation of a particular species of viridans streptococcus [9-11]. The results of these and similar schemes have shown clearly that within the viridans streptococci, Streptococcus oralis is a significant agent of infective endocarditis and a major pathogen in patients with attenuated host defence mechanisms [6, 10, 12-14]. The mechanisms by which $\mathrm{S}$. oralis causes this wide range of infections are as yet unclear, but the sialidase produced by this bacterium has been proposed as contributing towards the pathogenicity of several other micro-organisms, including S. pneumoniae, Salmonella typhimurium and Vibrio cholerae [15-17]. Bacterial sialidases cleave terminal, non-reducing sialic acid residues from sialoglycoconjugates. The precise role of these enzymes is unknown, but it has been suggested that they act as generalised virulence determinants [18] in that the release of sialic acid may expose cryptic carbohydrate binding sites for the invading organism $[19,20]$ and break down mucosal defence barriers of the host [21]. Furthermore, production of sialidase may be a critical factor in the provision of free sialic acid, a 
fermentable carbohydrate source for bacterial proliferation $[18,22,23]$. As a secondary consequence, sialic acid removal by these enzymes leads to direct damage to the host because of the central role of this sugar in cellular and molecular interactions [24].

In an attempt to identify virulence determinants of viridans streptococci causing serious infections, the possible role of the $\mathrm{S}$. oralis sialidase in disease processes was examined. As a first step towards understanding the role of sialidase as a putative virulence determinant, the sialidase was isolated from S. oralis and its properties were characterised.

\section{$M$ aterials and methods}

\section{Bacterial strain and maintenance}

S. oralis strain AR3, an isolate from infective endocarditis obtained from the London Hospital Medical College, was stored at $-70^{\circ} \mathrm{C}$ in vials containing cryopreservative (LabM, Salford, Lancs) and routinely maintained as described previously [22].

Medium and growth conditions for extracellular sialidase production

$B$ acterial colonies were removed from agar plates into $200 \mathrm{ml}$ of pre-reduced Tryptone Soya Broth (TSB; Oxoid) and incubated anaerobically until cultures had attained late exponential phase. This culture was used to inoculate $10 \mathrm{~L}$ of TSB and this culture was incubated aerobically at $37^{\circ} \mathrm{C}$ without agitation.

\section{Sialidase assay}

Sialidase activity was monitored throughout the purification process with a synthetic fluorogenic substrate, 2'-4-methylumbell iferyl- $\alpha$-D-N-acetylneuraminic acid (4-MU-NeuNAc; Sigma), as described previously [22]. The increase in relative fluorescence, caused by the release of 4-MU by the bacterial sialidase, was measured over time in a fluorimeter (Perkin Elmer LS3B, B eaconsfield, Bucks) with excitation and emission wavelengths set at $380 \mathrm{~nm}$ and $460 \mathrm{~nm}$, respectively. The release of 4-MU was quantified by comparison of relative fluorescence values with those obtained for standard concentrations of authentic methylumbelliferone.

\section{Protein determination}

The total protein concentration at each stage of the purification was determined by a bicinchoninic acid assay (Sigma) according to the manufacturer's instructions. A more rapid protein assay, the Coomassie Blue dye-binding assay (Pierce and Warriner, Chester, Cheshire) was used to screen for the presence of protein in column fractions. Coomassie Blue protein reagent $(100 \mu \mathrm{l})$ was added to $100 \mu \mathrm{l}$ of sample from column fractions in a microtitration tray and the $A_{620}$ was determined.

Purification of the extracellular sialidase of $S$. oralis

Stage I: culture supernate. Cells were removed from the culture of $\mathrm{S}$. oralis by means of an ultrafiltration unit fitted with a 0.16- $\mu \mathrm{m}$ cut-off membrane (Minisette, Flowgen Instruments, Lichfield, Staffordshire). EDTA, leupeptin, phenylmethylsulphonyl fluoride and pepstatin A (all purchased from Sigma) were added to the cell-free culture supernate at final concentrations of $100 \mu \mathrm{M}, 1 \mu \mathrm{M}, 200 \mu \mathrm{M}$ and $1 \mu \mathrm{M}$, respectively. All subsequent stages of the purification were performed at $4^{\circ} \mathrm{C}$ in $50 \mathrm{~mm}$ Tris- $\mathrm{HCl}$ buffer ( $\mathrm{pH} 7.0$ ) containing the listed protease inhibitors (buffer A). In the absence of protease inhibitors, extensive proteolytic degradation of the sialidase was observed.

Stage II: concentrated culture supernate. The culture supernate from stage I was concentrated 50 -fold to a volume of C. $200 \mathrm{ml}$ with an ultrafiltration unit (M innisette) fitted with a 10-kDa cut-off membrane.

Stage III: ammonium sulphate precipitate. The culture supernate from stage II was brought to $50 \%$ ammonium sulphate saturation with stirring and allowed to stand for $3 \mathrm{~h}$ before the precipitate was collected by centrifugation at $17600 \mathrm{~g}$ for $30 \mathrm{~min}$. The protein pellet, which contained $97 \%$ of the total sialidase activity, was dissolved in a small volume of buffer A. The preparation was dialysed against $6 \mathrm{~L}$ of this same buffer over $12 \mathrm{~h}$.

Stage IV: DEAE Trisacryl eluate. The retentate from stage III was applied to a column of DEAE Trisacryl M $(4.8 \times 15 \mathrm{~cm}$; Sepracor SA, Villeneuvre la Garenne Cedex, France) pre-equilibrated in buffer $A$. The column was washed with two bed volumes $(600 \mathrm{ml})$ of buffer $A$ and adsorbed proteins were eluted with $400-\mathrm{ml}$ volumes of this same buffer, each containing increasing concentrations of $\mathrm{NaCl}(0.05 \mathrm{M}, 0.10 \mathrm{M}$, $0.15 \mathrm{M}$ and $0.20 \mathrm{M}$ ), at a flow rate of $200 \mathrm{ml} / \mathrm{h}$. The eluted fractions $(8 \mathrm{ml})$ were assayed for sialidase activity and protein. The fractions eluting with $0.15 \mathrm{M}$ $\mathrm{NaCl}$, containing $>93 \%$ of the total sialidase activity, were pooled and concentrated to c. $4 \mathrm{ml}$ in a stirredcell ultrafiltration unit with a 10-kDa cut-off membrane (Flowgen).

Stage V: Ultrogel ACA-34 eluate. The concentrated preparation from stage IV was applied to a column of Ultrogel ACA $34(2.5 \times 100 \mathrm{~cm}$; Sepracor SA $)$ preequilibrated in buffer $A$ and proteins were eluted by this same buffer at a flow rate of $24 \mathrm{ml} / \mathrm{h}$. All fractions $(4.5 \mathrm{ml})$ were assayed for sialidase activity and protein. Sialidase-active fractions, at a protein concentration of $50 \mu \mathrm{g} / \mathrm{ml}$, were pooled and stored at $-70^{\circ} \mathrm{C}$, with no 
significant loss of enzyme activity detected after storage for 6 months.

\section{Further purification of the $S$. oralis sialidase}

Further purification of the $S$. oralis sialidase preparation from stage $V$ attempted by affinity chromatography with $\mathrm{N}$-( p-amino-phenyl) oxamic acid-agarose [25] and gel filtration on Sephacryl S-300 (Pharmacia, St Albans, Herts) in the presence of SDS resulted in no further purification of the enzyme when analysed by SDS-PAGE.

\section{Native PAGE and SDS-PAGE}

Native PAGE and SDS-PAGE $[26,27]$ analysis of the stage $V$ preparation and material from subsequent purification steps was performed in order to determine the purity of the enzyme and to estimate the mol. wt of the sialidase. Native and SDS-PAGE gels were run on two separate occasions in order to ascertain the purity and mol.wt of the purified sialidase. A self-casting, mini gel system $(105 \times 100 \mathrm{~mm}$; model MV 1 DC, A nachem, Luton) was used for PAGE analysis.

SDS-PAGE was performed with a resolving $7 \%$ gel. The purified sialidase (10 $\mu \mathrm{g}$ in the presence of SDS) was resolved at $100 \mathrm{~V}$ for $4 \mathrm{~h}$. Sialidase was located in the gel with 4-MU-NeuNAc [26]. Briefly, the gel was incubated in $0.2 \mathrm{M}$ sodium phosphate buffer $(\mathrm{pH} 7.0)$ containing Triton X-100 $10 \% \mathrm{v} / \mathrm{v}$ at $37^{\circ} \mathrm{C}$ for $2 \mathrm{~h}$ before spreading $500 \mu \mathrm{l}$ of $100 \mu \mathrm{M}$ 4-MU-NeuNAC over the surface of the gel. Sialidase activity was detected by the appearance of a fluorescent band, visualised with a UV light box $(\lambda=302 \mathrm{~nm}$; Biovision Transilluminator; Biogene, Kimbolton, Cambridgeshire). The image was captured with a high performance CCD camera linked to Bioscan Snapshot software (Datacell, Reading, Berkshire). A fter localisation of the sialidase activity, the gel was fixed and stained with Coomassie Brilliant Blue.

Native PAGE was performed with a resolving $6 \%$ gel. The purified sialidase (10 $\mu \mathrm{g}$ in non-denaturing buffer) was resolved by electrophoresis and localised in the gel as described for SDS-PAGE, except that Triton X-100 was omitted from the gel washing solution. The gel was stained for protein with a silver staining kit (Sigma) according to the manufacturer's instructions.

\section{Mol.wt determination by gel filtration}

The Ultrogel ACA-34 column used in the purification of the $S$. oralis sialidase was calibrated with mol.wt standards (Sigma) and the elution conditions described earlier. The void volume was determined from the elution position of blue dextran. Fractions $(3 \mathrm{ml})$ were collected and assayed for protein, and the elution volumes of the protein standards and the purified sialidase were recorded. This procedure was performed in triplicate to estimate the native mol.wt of the purified sialidase accurately.

\section{Substrate specificity of the $S$. oralis sialidase}

Sialyl- $\alpha 2,3-$ lactose, sialyl- $\alpha 2,6$-lactose, colominic acid (a polymer containing $\alpha 2,8$-linked $\mathrm{N}$-acetylneuraminic acid - N euNAC), bovine submaxillary mucin (BSM) (all purchased from Sigma), $\alpha_{1}$-acid glycoprotein (A GP; B io Products, Elstree) and 4-MU-NeuNAC were used to determine the substrate specificity of the purified enzyme. The sialic acids - NeuNAc and N-glycolylneuraminic acid (NeuNGc) - of the native glycoconjugates were quantified by high-pH anion-exchange chromatography with pulsed amperometric detection (HPAEC-PAD) with a DX-500 system (Dionex UK, Camberley, Surrey) after mild acid hydrolysis [28].

The enzymic release of sialic acids from glycoconjugates was determined from reaction mixtures $(1.0 \mathrm{ml})$ which contained $100 \mu \mathrm{l}$ of the stage $\mathrm{V}$ enzyme preparation and $10 \mu \mathrm{M}$ substrate with respect to bound NeuNAc or NeuNGc in $50 \mathrm{~mm} \mathrm{Tris-HCl}$ buffer $(\mathrm{pH}$ 7.0). The assays were incubated at $37^{\circ} \mathrm{C}$ and the initial rate of N euNAC or NeuNGC release was determined by HPAEC-PAD. The initial rate of release of 4-MU from 4-MU-NeuNAC was also quantified as described in the sialidase assay methodology; the concentration of 4MU-NeuNAC present and the proportion of enzyme preparation added to the total volume of the assay was comparable with other substrate specificity assays.

\section{Enzyme kinetics of the $S$. oralis sialidase}

The apparent $K_{m}$ and $V_{\max }$ for the purified enzyme were determined with AGP as substrate. The initial reaction velocity of $N$ euNAC release from $A G P$ over the substrate concentration range 10-300 $\mu \mathrm{M}$ NeuNAC was measured by HPAEC-PAD; the composition of the reaction mixture for the assay was as described above except that the total volume was scaled to $100 \mu \mathrm{l}$.

The fluorogenic assay for sialidase activity was employed to determine the $\mathrm{pH}$ optimum for the enzyme. Assays comprised: $35 \mu \mathrm{l}$ of $0.2 \mathrm{M}$ buffer (sodium citrate, $\mathrm{pH}$ 3.0-6.0; sodium phosphate, $\mathrm{pH}$ 6.0-8.0 and Tris- $\mathrm{HCl}, \mathrm{pH} 8.0-9.0), 25 \mu \mathrm{l}$ of $1 \mathrm{~mm} 4-$ MU-NeuNAC, an appropriate amount of enzyme preparation and distilled water to give a final volume of $100 \mu \mathrm{l}$. Assays were incubated at $37^{\circ} \mathrm{C}$ and the reaction was terminated by the addition of $100 \mu \mathrm{l}$ of $0.5 \mathrm{M}$ sodium carbonate buffer $(\mathrm{pH}$ 10.2) while the rate of increase in product formation was still linear with respect to time. Release of 4-MU was quantified and the $\mathrm{pH}$ optimum for sialidase activity was determined.

\section{Inhibition of the $\mathrm{S}$. oralis sialidase}

Inhibition of sialidase activity was examined with the fluorogenic assay for the enzyme described. 
Compounds used in inhibition assays were the metal salts $\mathrm{CuSO}_{4}, \mathrm{ZnSO}_{4}$ and $\mathrm{HgCl}_{2}$; the thiols cysteine$\mathrm{HCl}$, dithiothreitol and iodoacetate; the metabolic inhibitors $\mathrm{NaF}$ and chlorhexidine; the NeuNAc derivative 2,3-dehydro-NeuNAC; oxamic acid and the glycoprotein-derived monosaccharides $\mathrm{N}$-acetylglucosamine, mannose, galactose, $\mathrm{N}$-acetylgalactosamine, fucose and NeuNAc (all purchased from Sigma).

Inhibition assays comprised $15 \mu$ l of enzyme preparation and $15 \mu \mathrm{l}$ of 2 or $20 \mathrm{~mm}$ of the potential inhibitor in $50 \mathrm{~mm}$ Tris- $\mathrm{HCl}(\mathrm{pH} \mathrm{7.0)}$. The enzyme solution was incubated at room temperature for $5 \mathrm{~min}$ before the addition of $100 \mu \mathrm{l}$ of $100 \mu \mathrm{M}$ 4-MU-NeuNAC and $100 \mu \mathrm{l}$ of 2 or $20 \mathrm{~mm}$ of a listed compound or free sugar solution. A ssays were incubated at $37^{\circ} \mathrm{C}$ and the rate of 4-MU release was quantified. Sialidase activity over a range of 2,3-dehydro-NeuNAc concentrations $(0-5 \mu \mathrm{M})$ and at several substrate concentrations (20, 30 and $50 \mu \mathrm{M}$ 4-MU-NeuNAC) was quantified to determine the type of inhibition and the $\mathrm{K}_{\mathrm{IC}}$ for 2,3dehydro-N euNAC.

\section{Results}

Purification of the $\mathrm{S}$. oralis sialidase

Extracellular sialidase was purified from a late exponential phase culture of $\mathrm{S}$. oralis grown in TSB. Incubation of cultures beyond this stage led to degradation of the sialidase, due to the production of protease activities (data not shown). The enzyme was purified 4520 -fold by a combination of ammonium sulphate precipitation, ion- exchange and gel filtration chromatography. Table 1 summarises the activity, yield and fold-purification of the sialidase for each step.

Fractionation of the enzyme by anion-exchange chromatography (stage IV) is shown in Fig. 1. A small proportion of the total sialidase activity $(<6 \%$ of the total sialidase activity from stage III) eluted at $100 \mathrm{~mm}$ $\mathrm{NaCl}$, but these fractions were not investigated further. Most of the enzyme activity eluted with application of $150 \mathrm{~mm} \mathrm{NaCl}$ (fractions 175-188). Pooled active fractions were subjected to gel filtration chromatogra-

Table 1. Purification of the S. oralis sialidase

\begin{tabular}{|c|c|c|c|c|c|c|c|}
\hline Stage & Sialidase preparation & $\begin{array}{l}\text { Total } \\
\text { volume } \\
\text { (ml) }\end{array}$ & $\begin{array}{c}\text { Protein } \\
\text { concentration } \\
(\mathrm{mg} / \mathrm{ml})\end{array}$ & $\begin{array}{l}\text { Total activity } \\
\text { ( } \mu \mathrm{mol} 4-\mathrm{MU} \\
\text { released/min) }\end{array}$ & $\begin{array}{l}\text { Yield } \\
(\%)\end{array}$ & $\begin{array}{l}\text { Specific activity } \\
(\mathrm{nmol} 4-\mathrm{MU} \\
\text { released } / \mathrm{min} / \mathrm{mg} \\
\text { of protein) }\end{array}$ & $\begin{array}{c}\text { Fold } \\
\text { purification }\end{array}$ \\
\hline I & Culture supernate & 10000 & 3.59 & 2.87 & 100.0 & 0.08 & 1.0 \\
\hline II & Concentrated supernate & 420 & 3.51 & 2.68 & 93.1 & 1.82 & 22.8 \\
\hline III & $\left(\mathrm{NH}_{4}\right)_{2} \mathrm{SO}_{4}$ precipitate & 70 & 2.17 & 2.26 & 78.7 & 14.9 & 186.3 \\
\hline IV & DEAE Trisacryl & 103 & 0.12 & 2.12 & 73.8 & 171.1 & 2138.8 \\
\hline V & Ultrogel ACA-34 & 47 & 0.05 & 0.85 & 29.6 & 361.7 & 4521.3 \\
\hline
\end{tabular}

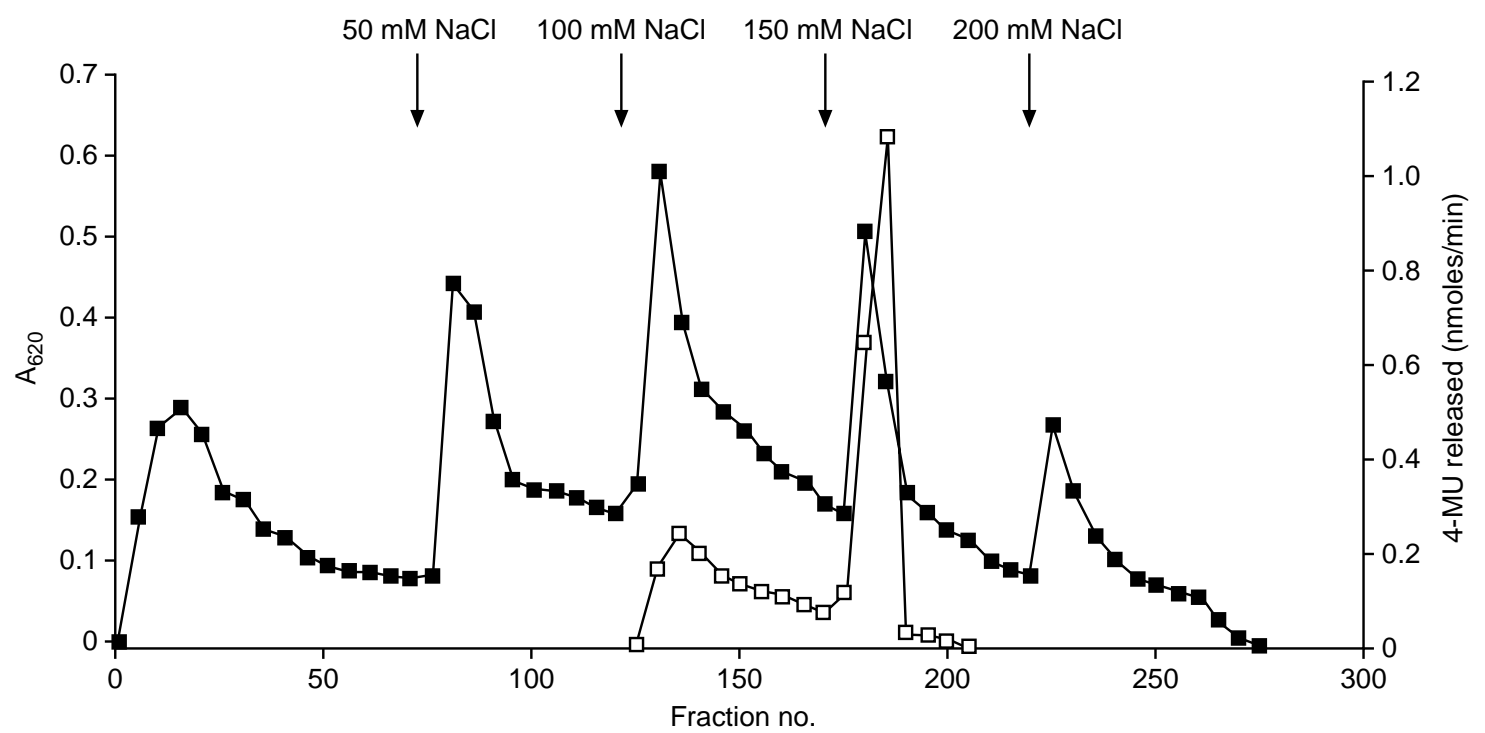

Fig. 1. Chromatography of the $S$. oralis sialidase on DEAE Trisacryl M. Proteins were eluted from a column of DEAE Trisacryl $\mathrm{M}$ at a flow rate of $200 \mathrm{ml} / \mathrm{h}$ by application of increasing concentrations of $\mathrm{NaCl}$ in buffer $\mathrm{A}$ (denoted by arrows). Fractions $(8 \mathrm{ml})$ were collected and assayed for protein $\left(A_{620} ; \mathbf{\square}\right)$ and sialidase activity $(4-\mathrm{MU}$ released; $\square)$. 
phy and the sialidase eluted as a distinct protein peak (fractions 127-136; Fig. 2).

Purity and mol.wt of the $\mathrm{S}$. oralis sialidase

The stage $V$ sialidase preparation had an apparent mol.wt of c. $329 \mathrm{kDa}$ as determined by gel filtration chromatography on Ultrogel ACA 34 calibrated with a range of mol.wt markers (Fig. 2). Native PAGE analysis of the enzyme demonstrated the presence of a single band with sialidase activity, as determined with the fluorogenic substrate (Fig. 3). After silver staining of the gel, one major band was apparent with a mol. wt of c. $322 \mathrm{kDa}$.

The enzyme exhibited a marked stability when heated at $100^{\circ} \mathrm{C}$ for $5 \mathrm{~min}$ in the presence of sample buffer containing SDS. A single band of enzyme activity was observed on gels stained with 4-MU-NeuNAc after reversal of SDS inhibition by treatment with Triton $X$ 100 (Fig. 4). However, protein staining of this gel demonstrated the presence of eight major protein bands, the sialidase-positive band had a mol. wt of $c$. $144 \mathrm{kDa}$.

Substrate specificity of the $\mathrm{S}$. oralis sialidase and enzyme kinetics

The activity of the sialidase against AGP was studied and data indicated that substrate cleavage followed typical Michaelis-M enten kinetics. Further analysis of these data indicated that the apparent $\mathrm{K}_{\mathrm{m}}$ value was
$11.8 \mu \mathrm{M}$ and the estimated $\mathrm{V}_{\max }$ was $0.12 \mathrm{nmol}$ $\mathrm{NeuNAc}$ released/min.

The substrate specificity of the $S$. oralis sialidase for a range of sialylated substrates is summarised in Table 2. The rates of cleavage of NeuNAc from sialyl- $\alpha 2,6$ lactose and colominic acid ( $\alpha 2,8$-sialyl-linked) relative to sialyl- $\alpha 2,3$-lactose (taken as 1.00) were calculated to be 0.54 and 0.44 , respectively. This demonstrates that the enzyme cleaves NeuNAc which is $\alpha 2,3$-linked to the adjacent monosaccharide in preference to $\alpha 2,6-$ or $\alpha 2,8$-linked. The relative rate of release of NeuNAC from the synthetic substrate 4-MU-NeuNAC was 0.86 , which is comparable to the relative rate determined for the release of NeuNAC from the natural substrate AGP, calculated as 1.11. Therefore, 4-MU-NeuNAC is an appropriate substrate to assay the activity of this bacterial sialidase, as the enzyme displays a similar specificity for this synthetic substrate as it does for the natural, physiologically relevant AGP. It is interesting to note that the sialidase cleaves NeuNGc as well as NeuNAc from sialoglycoconjugates. However, the enzyme preferentially cleaved neuraminic acid containing an $\mathrm{N}$-acetyl group over an $\mathrm{N}$-glycolyl group, as the rate of NeuNGC release from BSM was seven-fold slower than the rate of release of NeuNAc from BSM .

The purified sialidase was active against 4-MU$\mathrm{NeuNAc}$ over a wide $\mathrm{pH}$ range (4.0-9.0), but displayed $>80 \%$ of the maximal activity between pH 5.5 and 7.0 . The $\mathrm{pH}$ optimum was 6.0.

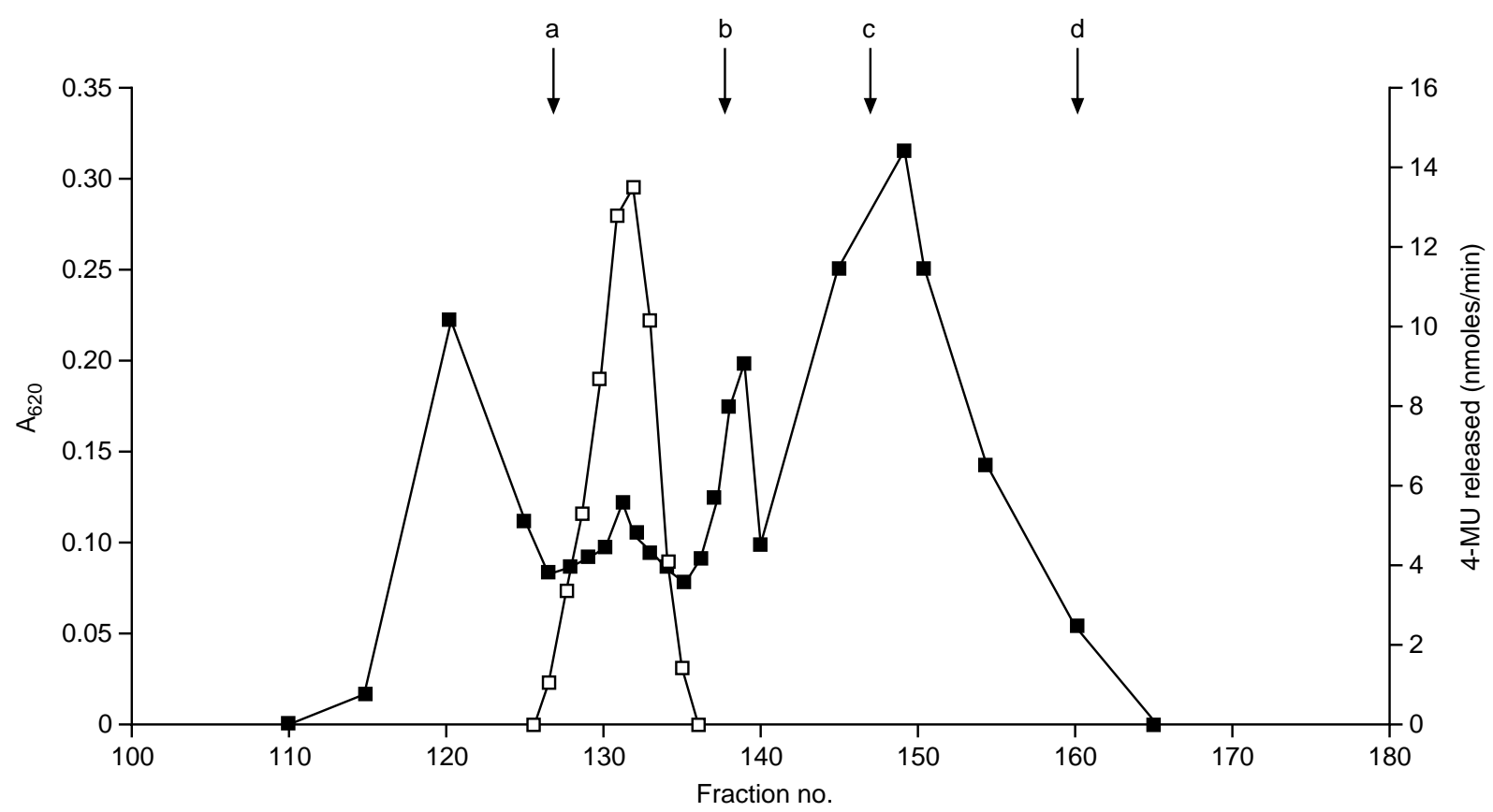

Fig. 2. Chromatography of the $S$. oralis sialidase on an UItrogel ACA 34. Proteins were eluted from a column of Ultrogel ACA 34 at a flow rate of $24 \mathrm{ml} / \mathrm{h}$ in buffer A. Fractions ( $3 \mathrm{ml}$ ) were collected and assayed for protein (A620; 口) and sialidase activity (4-MU released; $\square$ ). The column was calibrated with mol.wt markers: (a) apoferritin, $443 \mathrm{kDa}$; (b) $\beta$-amylase, $200 \mathrm{kDa}$; (c) serum albumin, $66 \mathrm{kDa}$; (d) carbonic anhydrase, $29 \mathrm{kDa}$; their elution positions are indicated by $\downarrow$. 


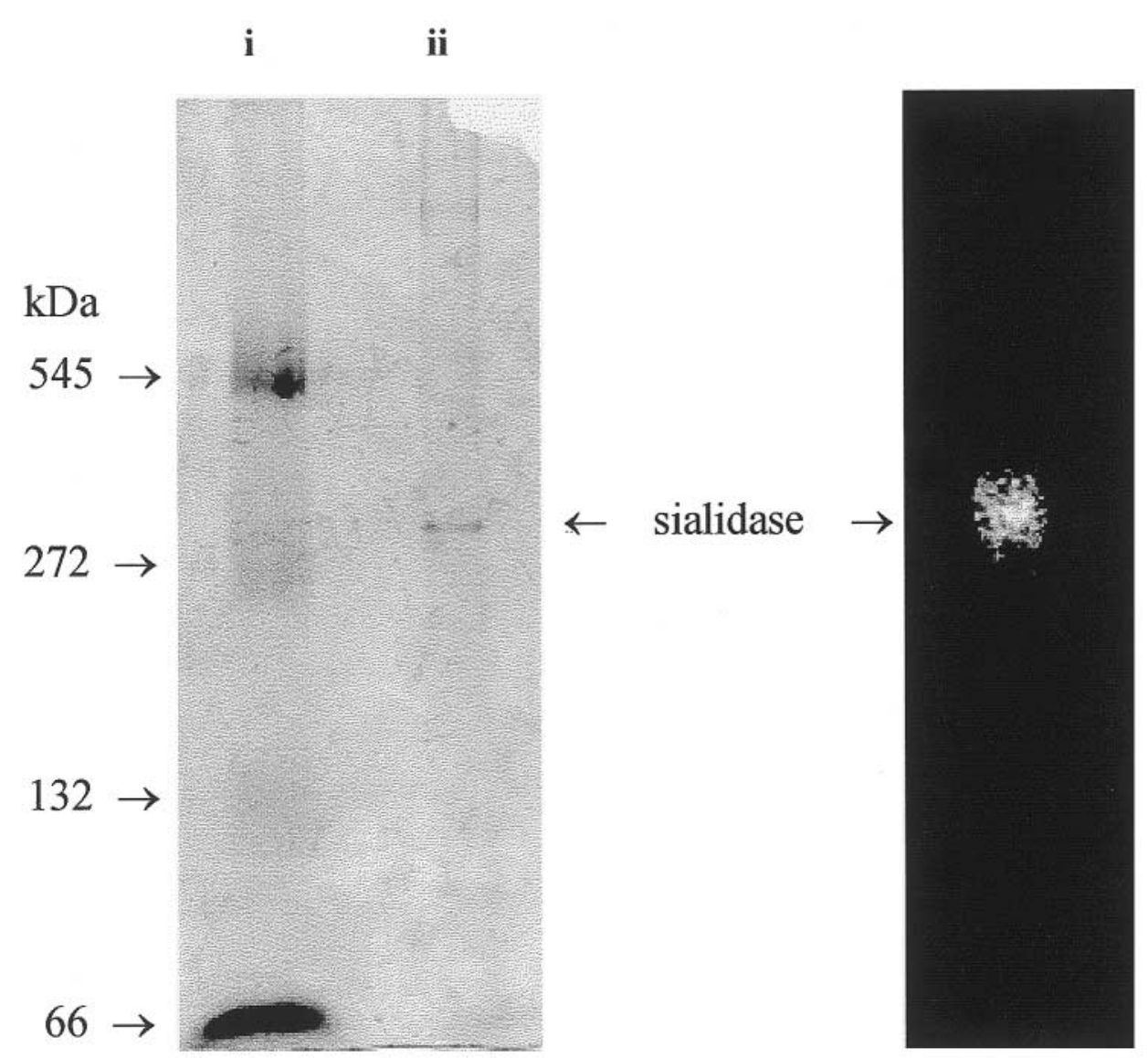

Fig. 3. Native PAGE analysis of the stage $\mathrm{V}$ sialidase. $\mathrm{A}, \mathrm{L}$ ane (i) mol.wt markers (urease dimer, $545 \mathrm{kDa}$ and monomer, $272 \mathrm{kDa}$ and bovine serum albumin dimer, $132 \mathrm{kDa}$ and monomer, $66 \mathrm{kDa}$ ); (ii) sialidase active band. The gel was stained for protein with silver stain. B, Sialidase activity, localised in the gel by the appearance of a fluorescent band when overlaid with $100 \mu \mathrm{m}$ 4-MU-NeuNAC.

\section{Inhibition of the $\mathrm{S}$. oralis sialidase}

$\mathrm{N}$-A cetylglucosamine, mannose, galactose, $\mathrm{N}$-acetylgalactosamine, fucose, $\mathrm{NeuNAC}, \mathrm{CuSO}_{4}, \mathrm{ZnSO}_{4}, \mathrm{HgCl}_{2}$, cysteine- $\mathrm{HCl}$, dithiothreitol, iodoacetate, $\mathrm{NaF}$, chlorhexidine and oxamic acid at final concentrations of 1 or $10 \mathrm{~mm}$ had no effect on sialidase activity. However, the NeuNAc derivative 2,3-dehydro-NeuNAc completely inhibited sialidase activity at a concentration of $1 \mathrm{~mm}$. The inhibitory effect of 2,3-dehydro-NeuNAc on sialidase was studied further by measuring enzyme activity against 4-MU-NeuNAC at various concentrations in the presence of this inhibitor over the concentration range $0-5 \mu \mathrm{M}$ (Fig. 5). It is evident from the Dixon plot that 2,3-dehydro-NeuNAC is a competitive inhibitor of sialidase, with a $\mathrm{K}_{\mathrm{IC}}$ of $1.2 \mu \mathrm{m}$.

\section{Discussion}

The virulence determinants associated with diseases caused by viridans streptococci are not well understood, and to date most research has focused on the organisms' ability to adhere to host tissues, aggregate platelets and resist host defences [6, 29-31]. Studies of several pathogenic micro-organisms have implicated sialidase as a major virulence determinant [32]. Sialidase is also produced by some viridans streptococci, including S. oralis [33], which is probably the most pathogenic species of this group, and the production of this enzyme may play a pivotal role in the preponderance of this organism in extra-oral infections. Therefore, the enzyme was isolated and purified to gain further insight into characteristics relevant to the disease process.

Earlier studies have indicated the inherent difficulties encountered in purifying sialidases of viridans streptococci to homogeneity. This was most notable for an organism described as ' $S$. sanguis', which could now be identified as $\mathrm{S}$. oralis or $\mathrm{S}$. mitis, where a high mol. wt aggregate containing sialidase was reported and purification to homogeneity was not achieved by conventional column chromatography $[34,35]$. Likewise, in the present study a high mol.wt aggregate (c. $325 \mathrm{kDa}$ ), which possessed sialidase activity, was isolated as determined by native PAGE and gel filtration chromatography. It was not possible to purify 
B

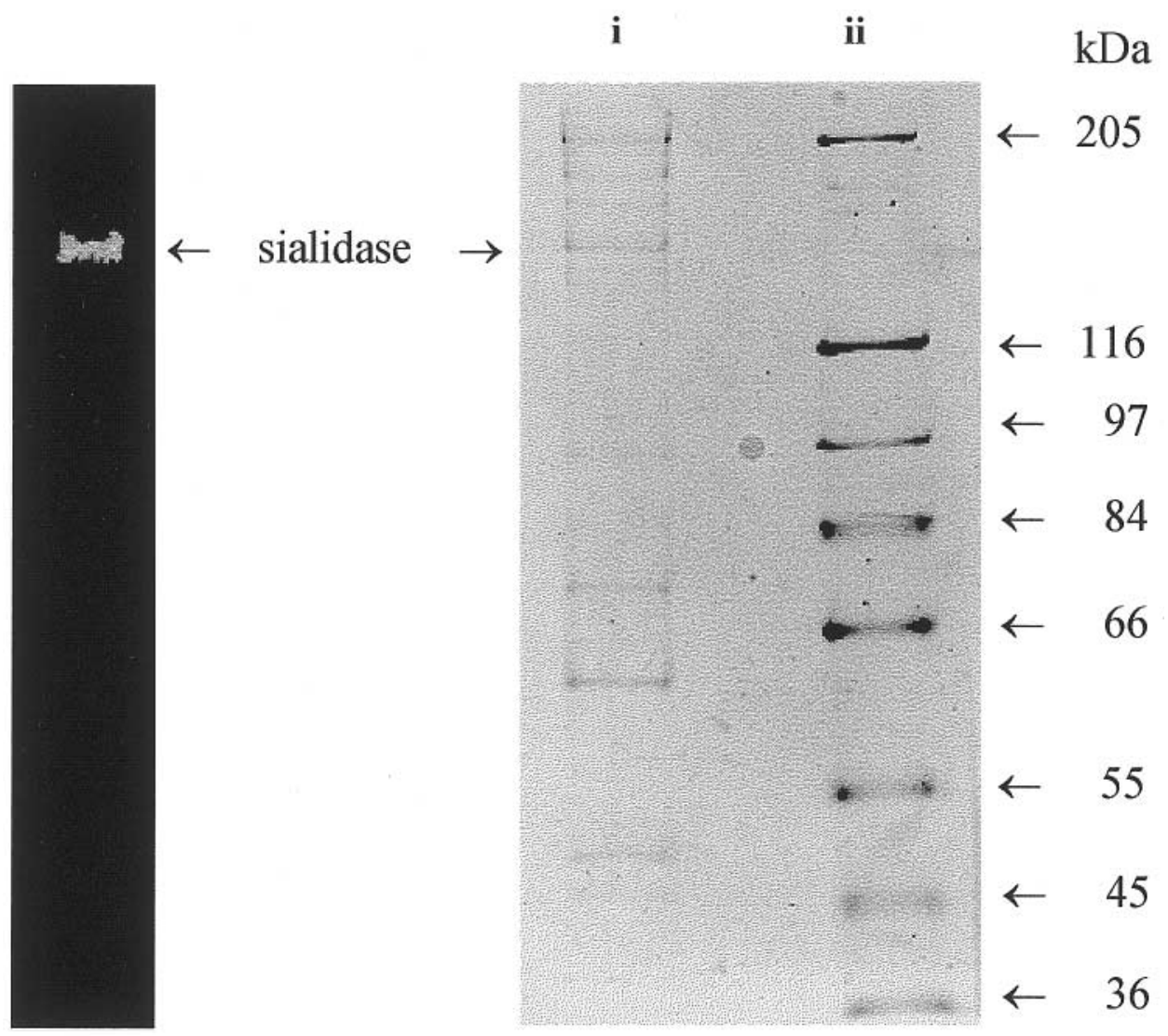

Fig. 4. SDS-PAGE analysis of the stage $V$ sialidase. A, Sialidase activity; localised in the gel by the appearance of a fluorescent band when overlaid with $100 \mu \mathrm{m}$ 4-MU-NeuNAC. B, Lane (i) sialidase active band and other purified proteins present in the stage $\mathrm{V}$ sialidase preparation; (ii) mol. wt markers (glyceraldehyde-3-phosphate dehydrogenase, $36 \mathrm{kDa}$; ovalbumin, $45 \mathrm{kDa}$; glutamic dehydrogenase, $55 \mathrm{kDa}$; albumin, $66 \mathrm{kDa}$; fructose-6-phosphate kinase, $84 \mathrm{kDa}$; phosphorylase b, $97 \mathrm{kDa}$; galactosidase, $116 \mathrm{kDa}$; myosin, $205 \mathrm{kDa}$ ). The gel was stained with Coomassie Brilliant Blue.

Table 2. Substrate specificity of the S. oralis sialidase

\begin{tabular}{lcc}
\hline Substrate & Sialyl-linkage & $\begin{array}{c}\text { Relative rate of } \\
\text { cleavage* }\end{array}$ \\
\hline Oligosaccharides and polysaccharides & \\
Sialyl- $\alpha 2,3$-lactose & $\alpha 2,3$ & 1.00 \\
Sialyl- $\alpha 2,6$-lactose & $\alpha 2,6$ & 0.54 \\
Colominic acid & $\alpha 2,8$ & 0.44 \\
Glycoproteins & $\alpha 2,3$ and $\alpha 2,6$ & 1.11 \\
AGP & $\alpha 2,6$ & 0.20 \\
BSM (N euNAC) & $\alpha 2,6$ & 0.03 \\
(N euNGC) & $\ldots$ & 0.86 \\
Synthetic & $\ldots$ & \\
4-MU-NeuNAC &
\end{tabular}

*Cleavage rates of NeuNAC presented relative to that obtained with sialyl- $\alpha 2,3$-lactose as substrate.

the sialidase any further from this aggregate. SDSPAGE analysis revealed the presence of several distinct proteins, the sialidase-positive band had a mol. wt of $c$. $144 \mathrm{kDa}$. The results from the non-denaturing and denaturing determinations of mol.wt and the demonstration of additional protein components by SDSPAGE suggest that sialidase is a component of a protein complex. The nature of this association is not clear, but a study on the extracellular sialidase of $\mathrm{V}$. cholerae has demonstrated that this enzyme forms a multi-enzyme complex, which contains other glycosidic and proteolytic activities [36]. Sialidase complexed with other enzymes, including $\beta$-galactosidase, is also found in human lysosomes [37]. A similar association may be present with respect to the $\mathrm{S}$. oralis sialidase, whereby glycosidic and proteolytic activities form a multi-enzyme complex. This could have significant physiological benefit for the bacteria in that the hydrolytic enzymes could interact in a concerted manner in the breakdown of host glycoproteins, facilitating adhesion of the organism to epithelial surfaces and circulatory glycoproteins, as well as supplying a nutrient source for the bacteria.

The sialidase resolved by SDS-PAGE had an apparent mol. wt of $144 \mathrm{kDa}$. A comparison of the properties of a variety of bacterial sialidases revealed that these enzymes are highly diverse with respect to mol. wt, isoelectric point, substrate specificity and specific activity [32]. However, despite these differences, conserved sequences have been demonstrated at the molecular level in bacterial sialidases [38]. Interestingly, the 


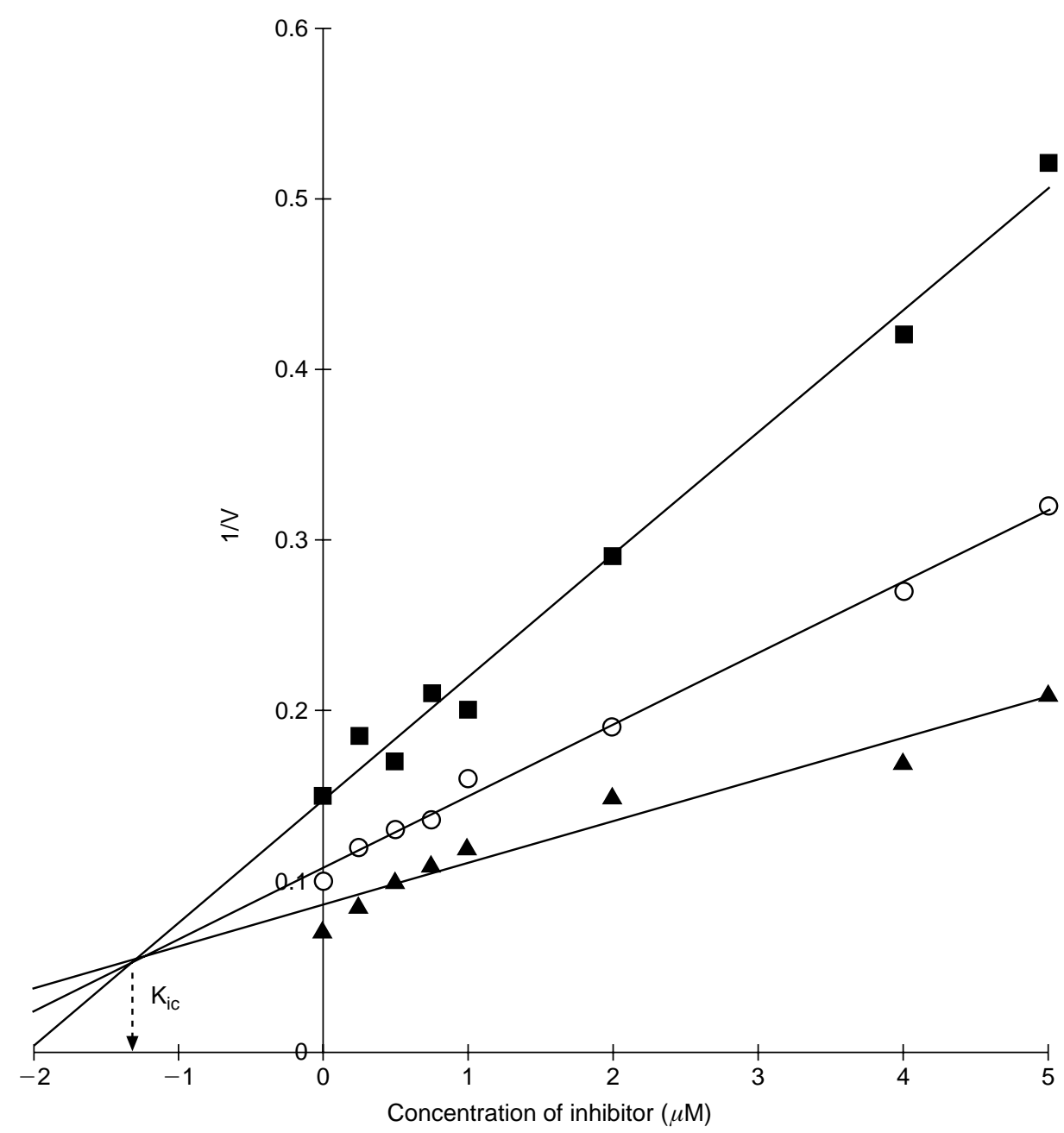

Fig. 5. Inhibition of the stage $V$ S. oralis sialidase by 2,3-dehydro-NeuNAc. The Dixon plot is shown where concentration of inhibitor [I] is expressed in $\mu \mathrm{M}$ and the reaction velocity $(\mathrm{V})$ is expressed in $\mathrm{nmol} 4-\mathrm{MU} \mathrm{released} / \mathrm{min}$. Data are shown for 2,3-dehydro-NeuNA C over a range of substrate (4-M U-NeuNA C) concentrations: $10 \mu \mathrm{M}(\mathbf{O}), 20 \mu \mathrm{M}$ $(\square)$ and $50 \mu \mathrm{M}(\mathbf{\Delta})$.

occurrence of sialidase in micro-organisms is frequently not in accordance with the phylogenetic relationship of bacterial species or strains. Highly related species or even strains of one species differ with respect to sialidase production $[39,40]$. Furthermore, these enzymes - which share sequence homologies - are common in animals and in diverse micro-organisms that mostly exist as animal commensals or pathogens. Therefore, the hypothesis has been proposed that sialidases have originated in higher animals and that bacteria have acquired this genetic information during association with their animal hosts by horizontal gene transfer mechanisms [41]. The diverse biochemical properties of sialidases may be a result of the sialidase gene evolving to occupy a particular biological niche. In the case of the $S$. oralis sialidase this could be to remove sialic acids from 0 and $\mathrm{N}$-linked glycoproteins as substrates for growth.

A large $\mathrm{pH}$ range could be tolerated by the $\mathrm{S}$. oralis sialidase (i.e., it was active between $\mathrm{pH} 4.0$ and 9.0) and it exhibited a pH optimum of 6.0, which is typical of that of other bacterial sialidases [32, 42]. The enzyme demonstrated a broad substrate specificity, cleaving $\alpha 2,3-, \alpha 2,6-$ and $\alpha 2,8-$ linked NeuNAc from a range of glycoprotein and oligosaccharide substrates. Furthermore, the purified enzyme cleaved NeuNGc from the naturally occurring substrate, BSM. However, NeuNGc (which is not found in healthy human tissues) was less susceptible to sialidase action than the $\mathrm{N}$ acetyl derivative, the most abundant sialic acid in man [24]. Similar characteristics have also been observed for a number of other bacterial sialidases [43]. Comparison of the kinetic properties of the purified sialidase of $\mathrm{S}$. oralis with other bacterial enzymes is difficult, as a range of substrates has been used and different assay conditions have been employed. Nevertheless, from the present data the sialidase has a low apparent $\mathrm{K}_{\mathrm{m}}$ of $10.2 \mu \mathrm{M}$ of total bound NeuNAc against the natural substrate human AGP, indicating the high affinity of the enzyme towards $\mathrm{N}$-linked, complex-type, sialylated glycoproteins.

It has been demonstrated that unconjugated NeuNAc will support growth of $\mathrm{S}$. oralis when supplied as the sole source of fermentable carbohydrate, with the 
concomitant induction of the intracellular enzymes required for the catabolism of this monosaccharide [22]. Furthermore, both the presence of an inducible transport system for NeuNAC and the pivotal role of sialidase in the degradation and utilisation of sialoglycoconjugates has recently been demonstrated for $S$. oralis $[44,45]$. When the highly sialylated glycoprotein AGP was used as a model, it was shown that the constituent NeuNAc was released by sialidase and catabolised as a source of fermentable carbohydrate. Additionally, as a result of this exo-glycosidic activity the glycan chains were opened to degradation by other glycosidases produced by this bacterium, therefore extending the fermentable carbohydrate source available. The dependence on the production of sialidase for the growth of $\mathrm{S}$. oralis on AGP was further supported by its inhibition in the presence of the sialidase inhibitor, 2,3-dehydro-NeuNAc. The important role of sialidase in the growth of bacteria on host glycoproteins in vivo has been demonstrated previously [23], where sialidase-deficient mutants of Bacteroides fragilis exhibited a reduced ability to grow in a rat pouch model. In the current study, a sialidase was isolated from $\mathrm{S}$. oralis and was shown to possess properties which may facilitate bacterial persistence in vivo, including a broad pH optimum and substrate specificity. Taken together, these studies provide compelling evidence for the presence of a highly integrated system for the release and metabolism of NeuNAc, which is likely to be important in the nutrition of this organism.

Studies are now being pursued to further characterise the high mol.wt aggregate, which contains sialidase activity, and to identify any associated components. Understanding the detailed molecular mechanisms by which bacteria proliferate may be important in the development of future intervention strategies, at a time when the need for alternative antimicrobial therapies is becoming increasingly important with the emergence of penicillin resistance within this group.

This work was supported in part by British Heart Foundation grant no. PG/95064 and the Joint Research Committee (King's College School of Medicine and Dentistry). We thank Bio Products Limited (Elstree, UK) for providing the sample of AGP.

\section{R eferences}

1. Bochud P-Y, Calandra T, Francioli P. Bacteremia due to viridans streptococci in neutropenic patients: a review. Am J Med 1994; 97: 256-264.

2. Awada $A$, van der Auwera $P, M$ eunier $F$, Daneau $D, K$ lastersky 1. Streptococcal and enterococcal bacteremia in patients with cancer. Clin Infect Dis 1992; 15: 33-48.

3. Bochud P-Y, Eggiman P, Calandra T, Van M elle G, Saghafi L, Francioli $P$. Bacteremia due to viridans streptococcus in neutropenic patients with cancer: clinical spectrum and risk factors. Clin Infect Dis 1994; 18: 25-31.

4. Classen DC, Burke JP, Ford CD et al. Streptococcus mitis sepsis in bone marrow transplant patients receiving oral antimicrobial prophylaxis. Am J Med 1990; 89: 441-446.

5. Cohen J, Donnelly JP, Worsley A M, Catovsky D, Goldman JM, Galton DA. Septicaemia caused by viridans streptococci in neutropenic patients with leukaemia. Lancet 1983; 2: 1452- 1454.
6. Douglas CWI. Pathogenic mechanisms in infective endocarditis. Rev Med Microbiol 1993; 4: 130-137.

7. M CW hinney PHM, Gillespie SH, Kibbler CC, Hoffbrand AV, Prentice HG. Streptococcus mitis and ARDS in neutropenic patients. Lancet 1991; 337: 429.

8. M CW hinney PHM, Patel S, Whiley RA, Hardie JM, Gillespie $\mathrm{SH}, \mathrm{Kibbler} \mathrm{CC}$. Activities of potential therapeutic and prophylactic antibiotics against blood culture isolates of viridans group streptococci from neutropenic patients receiving ciprofloxacin. Antimicrob Agents Chemother 1993; 37: 2493-2495.

9. Beighton D, Hardie JM, Whiley RA. A scheme for the identification of viridans streptococci. J Med Microbiol 1991; 35: $367-372$.

10. Hardie JM, Whiley RA. Recent developments in streptococcal taxonomy: their relation to infections. Rev Med Microbiol 1994; 5: 151-162.

11. Kilian M, Mikkelsen L, Henrichsen J. Taxonomic study of viridans streptococci: description of Streptococcus gordonii sp. nov. and emended descriptions of Streptococcus sanguis (White and Niven 1946), Streptococcus oralis (Bridge and Sneath 1982), and Streptococcus mitis (Andrewes and Horder 1906). Int J Syst Bacteriol 1989; 39: 471-484.

12. Beighton D, Carr AD, Oppenheim BA. Identification of viridans streptococci associated with bacteraemia in neutropenic cancer patients. J Med Microbiol 1994; 40: 202-204.

13. Jacobs JA, Schouten $H C$, Stobberingh $E E$, Soeters $P B$. Viridans streptococci isolated from the bloodstream. Relevance of species identification. Diagn Microbiol Infect Dis 1995; 22: 267-273.

14. West PWJ, AI-Sawan R, Foster HA, Electricwala Q, Alex A Panigrahi $D$. Speciation of presumptive viridans streptococc from early onset neonatal sepsis. I Med Microbiol 1998; 47: 923- 928.

15. Berry AM, Paton JC, Glare EM, Hansman D, Catchside DE. Cloning and expression of the pneumococcal neuraminidase gene in Escherichia coli. Gene 1988; 71: 299-305.

16. Galen JE, Ketley JM, Fasano A, Richardson SH, Wasserman $\mathrm{SS}, \mathrm{K}$ aper JB. Role of Vibrio cholerae neuraminidase in the function of cholera toxin. Infect Immun 1992; 60: 406-415.

17. Hoyer LL, Roggentin P, Schauer R, Vimr ER. Purification and properties of cloned Salmonella typhimurium LT2 sialidase with virus-typical kinetic preference for sialyl $\alpha 2-3$ linkages. J Biochem 1991; 110: 462- 467.

18. Corfield T. Bacterial sialidases - roles in pathogenicity and nutrition. Glycobiology 1992; 2: 509-521.

19. Cacalano $G$, K ays M, Saiman L, Prince A. Production of the Pseudomonas aeruginosa neuraminidase is increased under hyperosmolar conditions and is regulated by genes involved in alginate expression. J Clin Invest 1992; 89: 1866-1874.

20. Gibbons RJ, Hay DI, Childs WC, Davis G. Role of cryptic receptors (cryptitopes) in bacterial adhesion to oral surfaces. Arch Oral Biol 1990; 35 Suppl: 107S-114S.

21. Gottschalk A. Correlation between composition, structure shape and function of a salivary mucoprotein. Nature 1960; 186: $949-951$.

22. Byers $H$, Homer KA, Beighton D. Utilization of sialic acid by viridans streptococci. J Dent Res 1996; 75: 1564- 1571.

23. Godoy VG, Dallas MM, Russo TA, Malamy $M H$. A role for Bacteroides fragilis neuraminidase in bacterial growth in two model systems. Infect Immun 1993; 61: 4415-4426.

24. Kelm S, Schauer R. Sialic acids in molecular and cellular interactions. In: A survey of cell biology (Int Rev Cytology 175). San Diego, Academic Press. 1997: 137-240.

25. Cuatrecasas $P$, Illiano, G. Purification of neuraminidases from Vibrio cholerae, Clostridium perfringens and influenza virus by affinity chromatography. Biochem Biophys Res Commun 1971; 44: 178- 184.

26. Berg W, Gutschker-Gdaniec G, Schauer R. Fluorescent staining of sialidases in polyacrylamide gel electrophoresis and ultrathin-layer isoelectric focusing. Anal Biochem 1985; 145: $339-342$

27. Laemmli UK. Cleavage of structural proteins during the assembly of the head of bacteriophage T4. Nature 1970; 227: $680-685$.

28. Lifely MR, Hale C, Boyce S, Keen MJ, Phillips J. Glycosylation and biological activity of CAMPATH- ${ }^{1} \mathrm{H}$ expressed in different cell lines and grown under different culture conditions. Glycobiology 1995; 5: 813-822. 
29. Baddour LM. Virulence factors among gram-positive bacteria in experimental endocarditis. Infect Immun 1994; 62: 2143-2148.

30. Gossling J. Occurrence and pathogenicity of the Streptococcus milleri group. Rev Infect Dis 1988; 10: 257- 285.

31. Herzberg MC. Platelet-streptococcal interactions in endocarditis. Crit Rev Oral Biol Med 1996; 7: 222-236.

32. Saito M, Yu RK. Biochemistry and function of sialidases. In Rosenberg A (ed) Biology of the sialic acids. New York Plenum Press. 1995: 261-313.

33. Beighton D, Whiley RA. Sialidase activity of the "Streptococcus milleri group" and other viridans group streptococci. I Clin Microbiol 1990; 28: 1431-1433.

34. Straus D, Portnoy-Duran C. Neuraminidase production by a Streptococcus sanguis strain associated with subacute bacterial endocarditis. Infect Immun 1983; 41: 507-515.

35. Varki A, Diaz S. A neuraminidase from Streptococcus sanguis that can release 0 -acetylated sialic acids. J Biol Chem 1983; 258: 12465-12471.

36. Stewart-Tull DES, Ollar RA, Scobie TS. Studies on the Vibrio cholerae mucinase complex. I. Enzymic activities associated with the complex. J Med Microbiol 1986; 22: 325-333.

37. Potier $M, M$ ichaud $L$, Tranchemontagne J, Thauvette $L$. Structure of the lysosomal neuraminidase- $\beta$-galactosidasecarboxypeptidase multienzymic complex. Biochem J 1990; 267: 197- 202.

38. Roggentin $P$, Schauer $R$, Hoyer LL, Vimr ER. The sialidase superfamily and its spread by horizontal gene transfer. Mol
Microbiol 1993; 9: 915-921.

39. Hoyer LL, Hamilton AC, Steenbergen SM, Vimr ER. Cloning, sequencing and distribution of the Salmonella typhimurium LT2 sialidase gene, nan $\mathrm{H}$, provides evidence for interspecies gene transfer. Mol Microbiol 1992; 6: 873-884.

40. Roggentin $P$, Kleineidam RG, Schauer $R$. Diversity in the properties of two sialidase isoenzymes produced by Clostridium perfringens spp. Biol Chem Hoppe Seyler 1995; 376: 569- 575 .

41. Schauer R, V liegenthart JFG. Introduction. In: Schauer R (ed) Sialic acids - chemistry, metabolism and function. New York Springer. 1982: 1- 3.

42. Homer KA, Whiley RA, Beighton D. Production of specific glycosidase activities by Streptococcus intermedius strain UNS35 grown in the presence of mucin. I Med Microbiol 1994; 41: 184-190.

43. Corfield AP, Veh RW, Wember M, Michalski J-C, Schauer R. The release of $\mathrm{N}$-acetyl- and $\mathrm{N}$-glycoloyl-neuraminic acid from soluble complex carbohydrates and erythrocytes by bacterial, viral and mammalian sialidases. Biochem J 1981; 197: 293-299.

44. Byers $\mathrm{HL}$, Homer KA, Tarelli $\mathrm{E}$, Beighton D. N-acetylneuraminic acid transport by Streptococcus oralis strain AR3. I Med Microbiol 1999; 48: 375-381.

45. Byers HL, Tarelli E, Homer KA, Beighton D. Sequential deglycosylation and utilization of the $\mathrm{N}$-linked, complex-type glycans of human $\alpha_{1}$-acid glycoprotein mediates growth of Streptococcus oralis. Glycobiology 1999; 9: 469-479. 